\title{
Correlates of Prevalent Disability Among HIV-Infected Elderly Patients
}

\author{
José Alberto Ávila-Funes,,2 Pablo Francisco Belaunzarán-Zamudio,,4 Oscar Tamez-Rivera, \\ Brenda Crabtree-Ramírez, ${ }^{3}$ Ana Patricia Navarrete-Reyes, Jennifer Cuellar-Rodríguez, ${ }^{3}$ \\ Juan Sierra-Madero, ${ }^{3}$ and Hélène Amieva ${ }^{2}$
}

\begin{abstract}
The growing elderly population of HIV-infected patients is leading to a significant epidemiological transition and HIV infection has been proposed as a premature and accelerated aging model rending the individual more susceptible to premature disability. However, the determinants of disability among this emergent population are still lacking. Therefore, the aim of this study is to determine the correlates of prevalent disability in adults $\geq 50$ years with HIV infection. A cross-sectional study of 184 HIV-infected adults receiving ambulatory care in an HIV clinic of a tertiary care, university-affiliated hospital in Mexico City was conducted. Disability for instrumental (IADL) and basic activities of daily living (ADL) was established. Sociodemographic factors, clinical variables, current $\mathrm{CD}^{+}$cell count, and HIV viral load (VL) were tested as potential determinants of disability. Multivariate logistic regression analyses were used to identify the correlates of both types of disability. The mean age was 59.3 years. All participants were receiving highly active antiretroviral therapy. Of participants $17.9 \%$ had disability for IADL and $26.1 \%$ for ADL. Multivariate logistic regression analyses indicated that being older; having a lower $\mathrm{CD}^{+}$cell count, and having a detectable HIV VL were independently associated with both types of disability. In addition, educational level was also independently associated with ADL disability. Age, educational level, low $\mathrm{CD}^{+}$cell count, and detectable HIV VL were independently associated with disability. Whether effective and timely antiretroviral therapy will reduce the risk of disability in HIV-infected elderly patients needs to be evaluated.
\end{abstract}

\section{Introduction}

A GING WITH HUMAN IMMUNODEFICIENCY VIRUS (HIV) infection is a current reality. The growing elderly population of HIV-infected patients is leading to a significant epidemiological transition characterized by an increased prevalence and incidence of HIV infection among subjects $\geq 50$ years. The Centers for Disease Control estimate that approximately $30 \%$ of people currently living with HIV/AIDS in the United States are $\geq 50$ years of age whereas in Mexico, according to the Mexican National HIV/AIDS Agency (CENSIDA), $13 \%$ of HIV-infected patients are now 50 years old or older. ${ }^{1,2}$ Moreover, it is expected that by the year 2020 , subjects in this age group will represent more than $50 \%$ of the infected population worldwide. HIV infection has been proposed as a premature and accelerated aging model rending the individual more susceptible to age-related comorbidities as well as to premature disability. ${ }^{3-6}$

Functional independence is critical for an individual to preserve his or her autonomy. It is also an important determinant of health-related quality of life. Disability may be a manifestation of multisystem dysfunction, and it has generally been associated with catastrophic consequences for health among elderly individuals. ${ }^{7}$ The possible synergistic adverse effects of HIV infection and aging on daily functioning, including basic and instrumental activities of daily living (ADL), have been previously reported. ${ }^{5}$ Disability for ADL and instrumental activities of daily living (IADL) has been shown to add functional information to that obtained by classical assessment tools such as the ECOG PS and Karnofsky PS in special populations. For example, about $20 \%$ of older patients with cancer will be classified as having an

\footnotetext{
${ }^{1}$ Departmento of Geriatría, Instituto Nacional de Ciencias Médicas y Nutrición Salvador Zubirán, Mexico City, Mexico.

${ }^{2}$ Centre de Recherche Inserm, U897, Bordeaux, France and University Victor Segalen Bordeaux 2, Bordeaux, France.

${ }^{3}$ Departmento de Infectología, Instituto Nacional de Ciencias Médicas y Nutrición Salvador Zubirán, Mexico City, Mexico.

${ }^{4}$ División de Investigación de la Facultad de Medicina, Universidad Nacional Autónoma de México, Mexico City, Mexico.
} 
ECOG PS of at least 2; however, more than $50 \%$ of these patients will also need assistance for one or more IADL. ${ }^{8-10}$ Furthermore, ADL and IADL disability has been strongly related to poor health-related quality of life, hospitalization, and mortality. Physical frailty is a known cause of disability, and it explains up to $36 \%$ and $39 \%$ of IADL and ADL disability, respectively. ${ }^{11}$ Nonetheless, information on the determinants of disability among HIV-infected elderly patients is still lacking. The present study aims to identify the correlates of disability in adults $\geq 50$ years with HIV infection or AIDS. A secondary objective was to establish the prevalence of disability in this population.

\section{Materials and Methods}

\section{Study population}

This was a cross-sectional study that included HIVinfected participants $\geq 50$ years of age receiving care at the HIV clinic of a tertiary care, university-affiliated hospital in Mexico City. Potential participants were identified through the HIV/AIDS Clinic database and through the HIV/AIDS clinic appointment schedules/records. Participants were recruited between March 1, 2013 and February 28, 2014. Eligible subjects had to be at least 50 years old and to have documented HIV infection. Subjects with class III-IV heart failure by the New York Heart Association functional classification, class III-IV chronic obstructive pulmonary disease according to the Global Initiative for Chronic Obstructive Lung Disease classification, stage III-IV rheumatoid arthritis according to the American College of Rheumatology classification, stage 4-5 Parkinson's disease according to the Hoehn and Yahr scale as well as patients with history of ischemic and/or embolic cerebrovascular disease with motor sequelae, myocardial ischemia in the previous 3 months, severe dementia, and amputation of any upper and/or lower limb were excluded in order to avoid the inclusion of subjects with physical frailty due to chronic diseases other than HIV. Subjects were invited to voluntarily participate in the study through an informed consent process carried out in the clinic during the day of their scheduled visit for HIV care. A comprehensive geriatric assessment (CGA) was applied to all participants by trained staff using standardized methods, and included the evaluations described below. The Institute's Ethics Committee reviewed and approved the study protocol.

\section{Disability}

Two measurements of disability were investigated as outcomes: IADL and ADL. For IADL, the Lawton and Brody scale was used; participants responded as to whether they were able to perform eight activities of daily living that included using a telephone, being responsible for their own medication, managing money, using public or private transportation, shopping, housekeeping, cooking, and doing laundry (the last three items were asked to both men and women if they reported having carried out such activities in the past). ${ }^{12}$ For ADL, participants were asked if they needed help for any of the tasks on the Barthel ADL index (bathing, dressing, transferring from bed to chair, climbing stairs, toileting, continence, and feeding). ${ }^{13}$ Participants were considered as having IADL or ADL disability if they were unable to perform one or more activities, for each domain of disability, without help.

\section{Covariates}

Sociodemographic variables included age, sex, marital status, and educational level. Participants were asked whether they had a physician's diagnosis of diabetes, hypertension, dyslipidemia, cancer, myocardial ischemia, stroke, chronic obstructive pulmonary disease, cirrhosis, osteoarthritis, arthritis, osteoporosis, or chronic kidney disease. The presence of each of these diseases was summed up in a score ranging from 0 to 12 where a higher score indicates more chronic disease. A history of an AIDS-defining event was retrieved from medical charts (yes or no). Body mass index [BMI= weight $\left.(\mathrm{kg}) / \mathrm{height}(\mathrm{m})^{2}\right]$ was calculated from direct measures. Smoking status (current-former or never) and alcohol intake (current-former or never) were also investigated.

Depressive symptoms were assessed using the Geriatric Depression Scale (GDS); a score of $>5$ points indicated their presence. ${ }^{14}$ The Mini-Mental State Examination (MMSE) (score ranging from 0 to 30) was used to assess global cognitive function, and cognitive impairment was considered when a score $<24$ points was found. ${ }^{15}$ The number of prescription drugs was also recorded. The measurement that was closer to the date of the CGA was included for primary analysis and considered as the current $\mathrm{CD}^{+}$cell count. Current $\mathrm{CD}^{+}$cell counts were treated as a continuous variable but also as a binary one ( $<200$ cells $/ \mathrm{ml}$ cutoff point). All $\mathrm{CD}^{+}$T-lymphocyte counts included in this study were no more than a month old. In addition, $\mathrm{CD} 4^{+}$cell nadir values (the lowest measure registered) were considered for analysis. HIV viral load (VL) was measured using the Roche Amplicor or Abbot real time PCR with a lower limit of detection of $<40$ or $<20$ copies/ml, respectively. HIV RNA levels were included as a binary variable [undetectable vs. detectable]. The closest determination of HIV RNA levels to the CGA (no more than a month old) was considered for the analysis. In addition, time from HIV diagnosis and time on highly active antiretroviral therapy (HAART), both in years, were used as continuous covariates.

\section{Statistical analyses}

Variables were described using arithmetic means and standard deviations (SD) or frequencies and proportions. We compared the characteristics between disabled and nondisabled patients using the $\chi^{2}$ test, Fisher's exact test, or Student's $t$ test as appropriate. To develop an explanatory model for both types of disability, we fitted several multivariate logistic regression models including four variable blocks: sociodemographic factors, health-related factors, geriatric syndromes, and HIV/AIDS-related information. Wald tests were used to eliminate from every model those variables judged not significant at the $10 \%$ level and then the variables considered significantly associated with disability were retained. Second, a new model including the variables significantly associated with disability from previous models was run and the cut-off level at this time was $5 \%$ in order to select a set of variables to be included in a last full model. Based on these results, and as an unplanned analysis we explored the association between $\mathrm{CD} 4^{+}$cell counts and HIV VL with disability.

We organized four mutually exclusive groups as follows: (1) $\mathrm{CD}^{+} \geq 200$ and undetectable HIV VL, (2) $\mathrm{CD}^{+} \geq 200$ and detectable HIV VL, (3) $\mathrm{CD}^{+}<200$ and undetectable HIV 
VL, and (4) $\mathrm{CD} 4^{+}<200$ and detectable HIV VL. The groups were fitted in univariate and multivariate logistic regression models using disability as the dependent variable and the above-described categories as independent variables in order to explore the association of $\mathrm{CD} 4^{+}$cell counts and HIV VL with both types of disability adjusting for potential confounders (age, sex, chronic diseases, current smoking, current drinking, history of AIDS-defining event, time from HIV diagnosis, time on HAART, GDS score, and MMSE score). All comparisons were evaluated using 95\% confidence intervals (CI). Statistical analyses were performed in SPSS software for Windows (SPSS Inc., Chicago, IL, version 20.0).

\section{Results}

The study sample included 184 participants. Table 1 shows the sociodemographic characteristics and health status of participants. The mean age was 59.3 years $(\mathrm{SD}=7.0$; range 50 to 84 ) and $83.2 \%$ were men. All participants were receiving HAART at the moment of the study. Approximately $18 \%$ of participants $(17.9 \%)$ had disability for IADL and $26.1 \%$ for ADL. Dyslipidemia (57\%) and hypertension (33\%) were the most frequent chronic diseases. The mean time from HIV diagnosis was $11(\mathrm{SD}=6.4)$ years, whereas the mean time on HAART was $8.0(\mathrm{SD}=5.7)$ years. The mean nadir of $\mathrm{CD} 4^{+}$cell count was $151.6(\mathrm{SD}=128.6$; range 3 to 599). The mean current $\mathrm{CD} 4^{+}$cell count was 478.8 ( $\mathrm{SD}=236.7$; range 38 to 1,168 ). The current $\mathrm{CD} 4^{+}$cell count $<200$ was present in $11.4 \%$ of individuals and the current detectable HIV VL was found in $12.4 \%$ of them. The simultaneous current $\mathrm{CD}^{+}$cell count $<200$ and detectable HIV VL was present in only seven participants (3.8\%).

Univariate analyses showed that the four mutually exclusive subgroups created according $\mathrm{CD}^{+}$cell count and $\mathrm{VL}$

Table 1. Comparative Analyses of Participants According to the Activities of Daily Living or Instrumental Activities of Daily Living Disability

\begin{tabular}{|c|c|c|c|c|c|c|c|}
\hline Variable & All $\mathrm{n}=184$ & $\begin{array}{c}\text { Without ADL } \\
\text { disability } \\
\mathrm{n}=136 \\
(73.9 \%)\end{array}$ & $\begin{array}{c}\text { With ADL } \\
\text { disability } \\
\mathrm{n}=48 \\
(26.1 \%)\end{array}$ & $\mathrm{p}$ & $\begin{array}{l}\text { Without IADL } \\
\text { disability } \\
\mathrm{n}=151 \\
(82.1 \%)\end{array}$ & $\begin{array}{c}\text { With IADL } \\
\text { disability } \\
\mathrm{n}=33 \\
(17.9 \%)\end{array}$ & $\mathrm{p}$ \\
\hline Age, mean (SD) & $59.3(7.0)$ & $58.2(6.8)$ & $61.2(7.4)$ & 0.011 & $58.2(6.5)$ & $62.8(8.1)$ & 0.004 \\
\hline Male $(\%)$ & 83.2 & 80.1 & 91.7 & 0.067 & 84.1 & 78.8 & 0.460 \\
\hline $\begin{array}{l}\text { Educational level, } \\
\text { mean (SD) }\end{array}$ & $11.9(5.1)$ & $11.6(5.1)$ & $13.0(4.9)$ & 0.090 & $12.2(4.9)$ & $10.8(5.4)$ & 0.154 \\
\hline Stable partner $(\%)$ & 30.4 & 30.1 & 31.3 & 0.886 & 29.8 & 33.3 & 0.690 \\
\hline $\begin{array}{l}\text { High blood } \\
\text { pressure }(\%)\end{array}$ & 33.2 & $58.2(6.8)$ & $61.2(7.4)$ & 0.011 & 29.8 & 48.5 & 0.039 \\
\hline Dyslipidemia (\%) & 57.1 & 58.1 & 54.2 & 0.637 & 57.6 & 54.5 & 0.747 \\
\hline Diabetes $(\%)$ & 19.6 & 19.9 & 18.8 & 0.868 & 17.2 & 30.3 & 0.086 \\
\hline $\begin{array}{l}\text { Number of chronic } \\
\text { diseases, }{ }^{\mathrm{a}} \text { mean (SD) }\end{array}$ & $1.6(1.4)$ & $1.5(1.3)$ & $1.8(1.7)$ & 0.137 & $1.5(1.3)$ & $2.0(1.8)$ & 0.052 \\
\hline $\begin{array}{l}\text { Body mass index, } \\
\text { mean }(S D)\end{array}$ & 24.7 (3.9) & 24.9 (3.9) & $23.9(3.8)$ & 0.145 & $24.8(3.9)$ & $24.0(3.8)$ & 0.329 \\
\hline $\begin{array}{l}\text { Hepatitis C virus } \\
\text { coinfection }(\%)\end{array}$ & 4.3 & 4.2 & 4.4 & 0.999 & 4.5 & 3.1 & 0.999 \\
\hline $\begin{array}{l}\text { Current or former } \\
\text { smoker }(\%)\end{array}$ & 21.3 & 20.6 & 23.4 & 0.684 & 22.0 & 18.2 & 0.628 \\
\hline $\begin{array}{l}\text { Current or former } \\
\text { drinker }(\%)\end{array}$ & 26.1 & 26.5 & 25.0 & 0.842 & 29.1 & 12.1 & 0.044 \\
\hline MMSE <24 (\%) & 10.4 & 10.4 & 10.4 & 0.999 & 7.9 & 21.9 & 0.028 \\
\hline $\begin{array}{l}\text { Depressive } \\
\text { symptoms (\%) }\end{array}$ & 12.0 & 11.0 & 14.6 & 0.514 & 9.9 & 21.2 & 0.080 \\
\hline $\begin{array}{l}\text { Time from HIV } \\
\text { diagnosis years, } \\
\text { mean (SD) }\end{array}$ & $11.0(6.4)$ & $10.9(6.0)$ & $11.4(7.5)$ & 0.713 & $11.3(6.3)$ & $9.7(6.9)$ & 0.205 \\
\hline $\begin{array}{l}\text { Time on HAART, } \\
\text { mean (SD) }\end{array}$ & $8.0(5.7)$ & $8.3(5.7)$ & $7.2(5.9)$ & 0.233 & $8.3(5.6)$ & $6.8(6.1)$ & 0.167 \\
\hline $\begin{array}{l}\text { Nadir CD } 4^{+} \text {cell count, }{ }^{\mathrm{b}} \\
\text { mean (SD) }\end{array}$ & $151.6(128.6)$ & $156.2(128.4)$ & $138.7(129.7)$ & 0.420 & $158.4(126.6)$ & $120.7(135.2)$ & 0.150 \\
\hline $\begin{array}{l}\text { History of AIDS- } \\
\text { defining event }\end{array}$ & 32.2 & 29.0 & 41.3 & 0.125 & 29.0 & 46.9 & 0.050 \\
\hline $\begin{array}{l}\text { Current HIV RNA }<40 \\
\text { copies/ml }(\%)\end{array}$ & 88.0 & 92.6 & 75.0 & 0.001 & 91.4 & 72.7 & 0.006 \\
\hline $\begin{array}{l}\text { Current CD4 } 4^{+} \text {cell } \\
\text { count }<200(\%)\end{array}$ & 11.4 & 7.4 & 22.9 & 0.004 & 6.6 & 33.3 & $<0.00$ \\
\hline
\end{tabular}

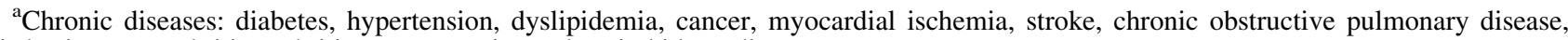
cirrhosis, osteoarthritis, arthritis, osteoporosis or chronic kidney disease.

${ }^{\mathrm{b}}$ Lowest $\mathrm{CD}^{+}$cell count measurement registered.

SD, standard deviation; ADL, activities of daily living; IADL, instrumental activities of daily living; MMSE, Mini-Mental State Examination; HAART, highly active antiretroviral therapy. 


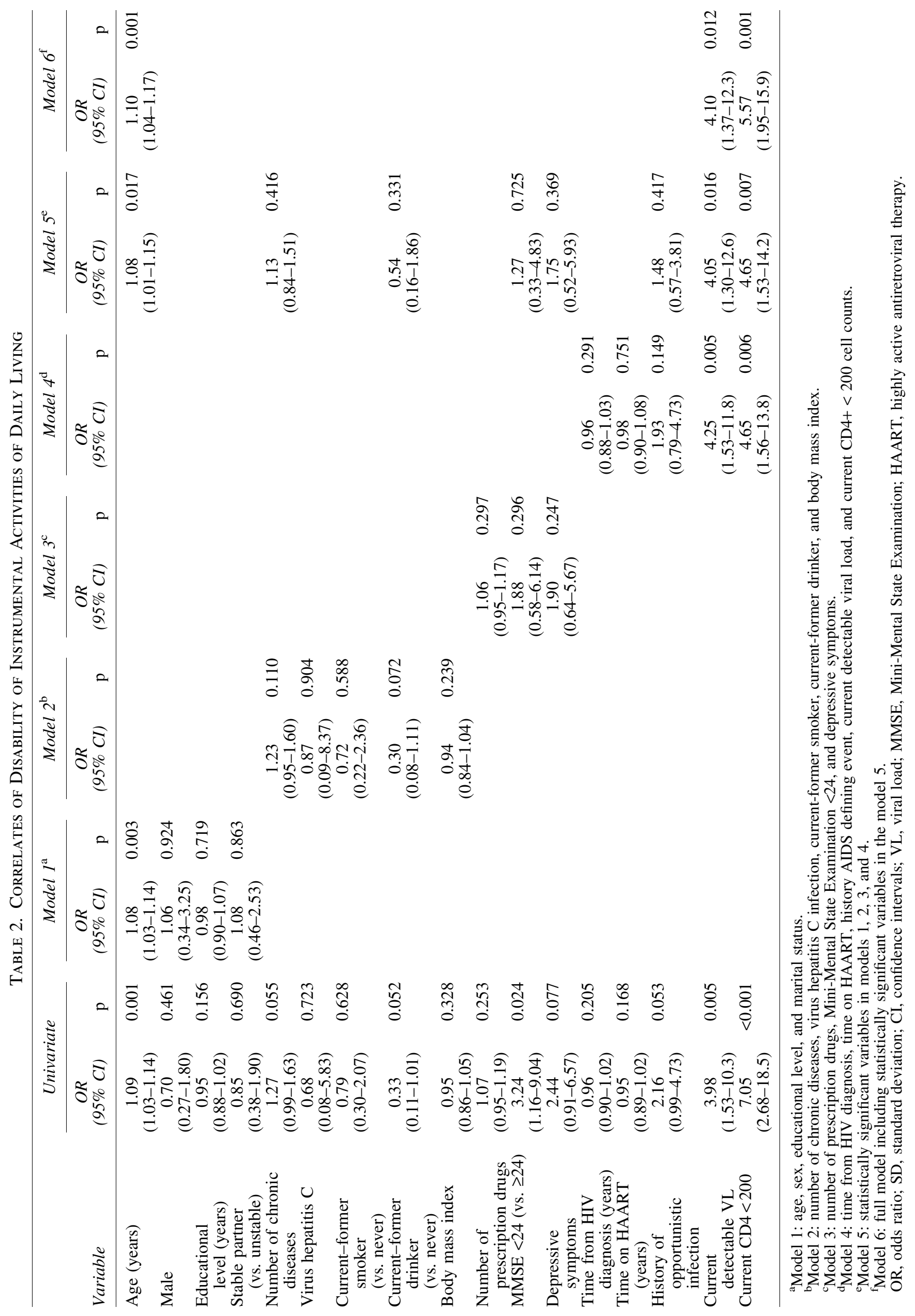


were not statistically different regarding age, sex, educational level, number of chronic diseases, global cognitive function, depressive symptoms, and time from HIV diagnosis or time on HAART. As expected, those with $\mathrm{CD}^{+}<200$ and detectable HIV VL had more disability for IADL $(p<0.001)$ and ADL $(p=0.002)$ in comparison to their counterparts in the other three subgroups.

Participants with IADL disability were older $(p=0.004)$, had a lower MMSE score $(p=0.028)$, and reported more chronic diseases $(p=0.052)$ when compared with their nondisabled counterparts. Patients with IADL disability were also more likely to have a history of an AIDS-defining event (46.9\% vs. $29.0 \% p=0.050)$ and less likely to have undetectable HIV VL (72.7\% vs. $91.4 \% p=0.006)$. Likewise, those with IADL disability had lower current $\mathrm{CD}^{+}$cell counts $(p<0.001)$. Similar results were found for ADL except for chronic diseases and a history of an AIDS-defining event, which were not statistically different. On the other hand, there were no differences regarding sex, educational level, marital status, hepatitis $\mathrm{C}$ virus coinfection, body mass index, depressive symptoms, nadir $\mathrm{CD}^{+}$cell count values, time from HIV diagnosis, or time on HAART for both types of disability (Table 1).

We present the correlates of IADL disability in Table 2. In the unadjusted logistic regression analysis we found that age $(p=0.001)$, lower MMSE $(p=0.024)$, detectable HIV VL $(p=0.005)$, and lower $\mathrm{CD}^{+}$cell count $(p<0.001)$ were significantly associated with prevalent IADL disability. Similarly, age $(p=0.013)$, detectable HIV VL $(p=0.002)$, and current $\mathrm{CD}^{+}<200(p=0.005)$ were associated with ADL disability (Table 3 ). In both models, current $\mathrm{CD}^{+}$cell counts, as continuous variable, were inversely associated with prevalent disability (results not shown).

In the multivariate model only age, detectable HIV VL, and current $\mathrm{CD}^{+}$cell count $<200$ were independently associated with both types of disability regardless of the number of chronic diseases, sex, body mass index, smoking status, alcohol intake, global cognitive function, or depressive symptoms, which were not statistically significant in any of the fitted models. In addition, educational level was also independently associated with disability for ADL.

Considering these results, we decided to separately assess the association between $\mathrm{CD}^{+}$cell counts $<200$ cells $/ \mu \mathrm{l}$ and detectable HIV VL with disability and their interaction (see Table 4). The results show that participants with current $\mathrm{CD}^{+}$cell counts $<200$ and detectable HIV VL were more likely to suffer from ADL or IADL disability when compared with participants with current $\mathrm{CD}^{+}$cell counts $\geq 200$ and undetectable HIV VL. Similarly, the subgroup of participants characterized only by detectable HIV VL was more likely to show ADL disability whereas those characterized only by current $\mathrm{CD}^{+}$cell counts $<200$ were more likely to have IADL disability. After adjusting for multiple potential confounders, only patients in both categories of detectable HIV VL (regardless of $\mathrm{CD}^{+}$cell count status) retained a statistically significant association with both types of disabilities. The association between the simultaneous presence of current $\mathrm{CD}^{+}$cell count $<200$ and detectable HIV VL and both types of disability was, however, remarkably stronger $(\mathrm{OR}=$ 48.2, $95 \%$ CI 5.41 to $429.59 ; p=0.001$, and $\mathrm{OR}=35.6,95 \%$ CI 4.70 to 269.35 ; $p=0.001$, for ADL and IADL, respectively) when compared with the strength of association ob- tained among participants showing only one of the conditions (current $\mathrm{CD}^{+}$cell count $<200$ or detectable HIV VL).

\section{Discussion}

In this study to estimate the prevalence of disability and associated factors among HIV-infected subjects aged 50 years and older, we observed that $17.9 \%$ of patients had IADL disability and $26.1 \%$ had disability for ADL. The prevalence of disability has been described as varying in different populations; in a cohort of Mexican communitydwelling elderly living in one of the districts of Mexico City, the reported prevalence of ADL and IADL disability was $13.3 \%$ and $35 \%$, respectively, ${ }^{16}$ while in the first round of Mexico's National Study on Health and Aging, ADL disability and IADL disability were found in $7.3 \%$ and $8.4 \%$ of community dwelling adults 60 years of age or older. ${ }^{17}$ The prevalence of disability found in the present study seems higher than that reported in community-dwelling older adults, particularly in the case ADL. On the other hand, as expected, well-known factors associated with disability such as age or educational level were more frequent and significantly associated with IADL and ADL disability or both.

Remarkably, we observed that markers of HIV disease progression such as low $\mathrm{CD}^{+}$cell count and detectable HIV viral load have a stronger and independent association with both types of disability than other factors, including age. In particular, the simultaneous presence of $\mathrm{CD}^{+}$cell count $<200$ cells/ $\mu$ l and detectable HIV VL was robustly associated with ADL and IADL disability. To our knowledge, this is one of the few studies to explore, with the use of validated tools and in a cohort study specifically designed for this purpose, the determinants of disability, including biomarkers of HIV disease progression, among HIV-infected elderly subjects.

Considering the limitations of the study, we do not have a clear explanation for the strong association observed between low $\mathrm{CD}^{+}$cell counts and detectable HIV VL and disability. A possible explanation is the loss of muscle mass. ${ }^{18} \mathrm{CD}^{+}$ cell count decline and HIV replication have been previously implicated in the loss of muscle mass, ${ }^{19}$ and the improvement of $\mathrm{CD}^{+} \mathrm{T}$-lymphocyte count has been associated with gains of lean mass. ${ }^{20}$ Moreover, changes in body composition due to HIV infection are similar to those observed during the aging process and include a decline in lean muscle mass, augmented protein catabolism, accumulation of visceral adipose tissue, and loss of bone mineral density. ${ }^{21-23}$

These changes have been associated with decreased muscle strength ${ }^{24,25}$ and with an elevated mortality risk in subjects with HIV infection, ${ }^{26}$ even among those on HAART, ${ }^{27}$ and could have a negative impact on muscle function and contribute to poor physical performance. ${ }^{28}$ The impairment in skeletal muscle repair, loss of muscle precursor cells, and the presence of fibrosis could promote functional impairment and disability in subjects $>50$ years old with HIV/AIDS. ${ }^{29}$ We consider that the stronger association between detectable HIV VL and disability, regardless of $\mathrm{CD}^{+}$cell count levels, may give support to this hypothesis. Muscle mass determinations were not available for this study population and we acknowledge this as a limitation.

Another limitation of the present study is its crosssectional nature precluding the establishment of direction regarding the association between current low $\mathrm{CD}^{+}$cell 


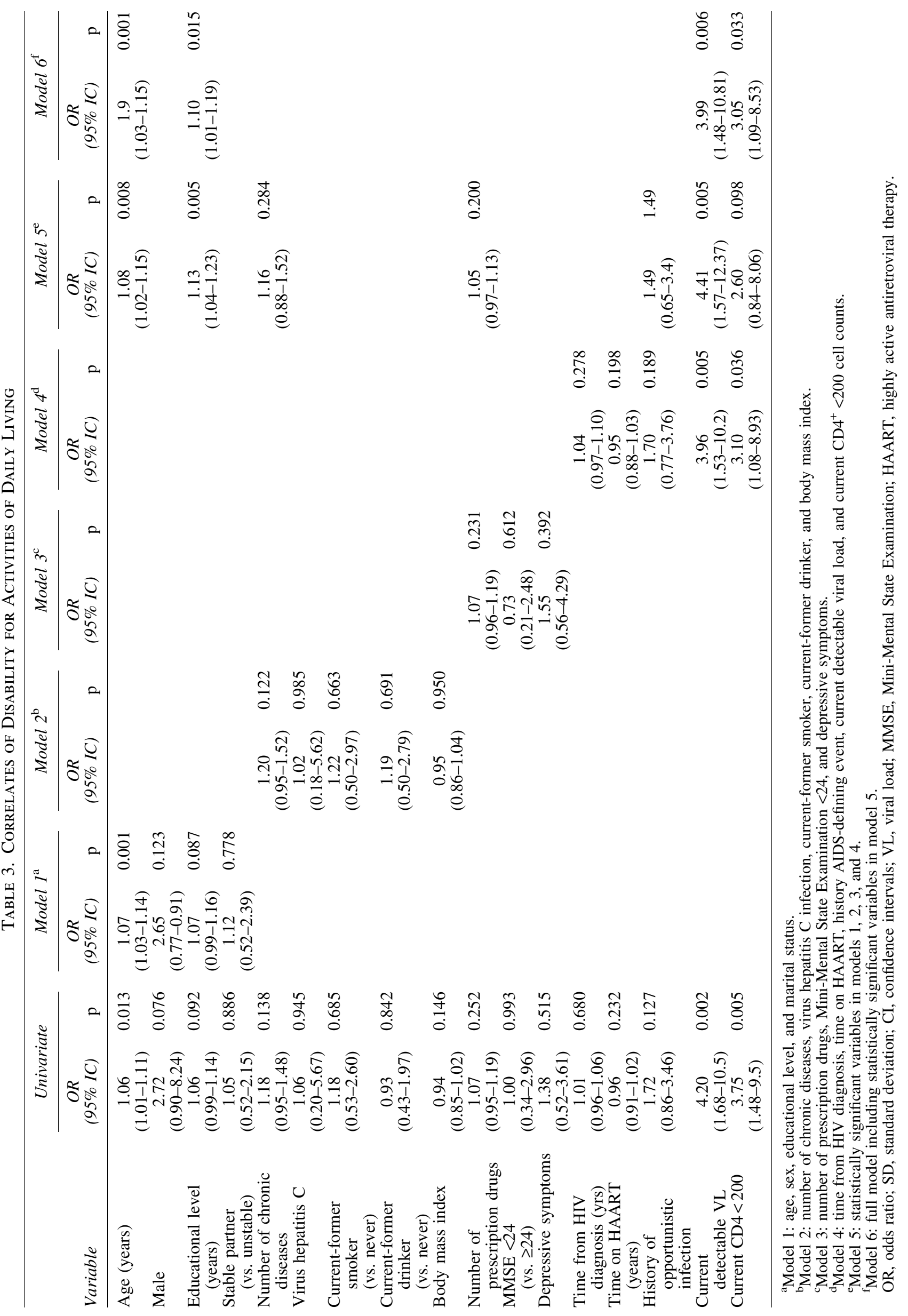


Table 4. Logistic Regression of Activities of Daily Living and Instrumental Activities of Daily living Disability According to the CD4 ${ }^{+}$Cell Count and HIV Viral Load

\begin{tabular}{|c|c|c|c|c|c|c|}
\hline & \multicolumn{3}{|c|}{ ADL disability } & \multicolumn{3}{|c|}{ IADL disability } \\
\hline & $O R$ & $95 \% C I$ & $\mathrm{p}$ & $O R$ & $95 \% C I$ & $\mathrm{p}$ \\
\hline \multicolumn{7}{|l|}{ Unadjusted } \\
\hline $\mathrm{CD}^{+}$cell count $\geq 200$ and undetectable VL (ref) & 1 & - & - & 1 & - & - \\
\hline $\mathrm{CD} 4^{+}$cell count $\geq 200$ and detectable VL & 3.4 & 1.57 to 10.24 & 0.026 & 2.6 & 0.75 to 9.13 & 0.12 \\
\hline $\mathrm{CD}^{+}{ }^{+}$cell count $<200$ and undetectable VL & 2.9 & 0.95 to 9.15 & 0.061 & 5.4 & 1.68 to 17.41 & 0.0 \\
\hline \multirow[t]{2}{*}{$\mathrm{CD}^{+}$cell count $<200$ and detectable VL } & 9.8 & 1.82 to 53.19 & 0.008 & 18.1 & 3.26 to 100.1 & 0.001 \\
\hline & \multicolumn{3}{|c|}{ p-global 0.005} & \multicolumn{3}{|c|}{$p$-global 0.001} \\
\hline \multicolumn{7}{|l|}{ Adjusted $^{\mathrm{a}}$} \\
\hline $\mathrm{CD}^{+}$cell count $\geq 200$ and undetectable VL (ref) & 1 & - & - & 1 & - & $\overline{0}$ \\
\hline $\mathrm{CD}^{+}$cell count $\geq 200$ and detectable $\mathrm{VL}$ & 4.0 & 1.16 to 13.75 & 0.028 & 4.13 & 0.92 to 18.54 & \\
\hline $\mathrm{CD}^{+}{ }^{+}$cell count $<200$ and undetectable VL & 2.2 & 0.56 to 9.09 & 0.254 & 3.0 & 0.73 to 11.99 & 0.129 \\
\hline \multirow[t]{2}{*}{$\mathrm{CD}^{+}$cell count $<200$ and detectable VL } & 48.2 & 5.41 to 429.6 & 0.001 & 35.6 & 4.70 to 269.3 & 0.001 \\
\hline & \multicolumn{3}{|c|}{$p$-global 0.001} & \multicolumn{3}{|c|}{ p-global 0.002} \\
\hline
\end{tabular}

${ }^{a}$ Adjusted by age, sex, number of 12 chronic diseases, current smoking, current drinker, history of opportunist AIDS-associated infection, time from HIV diagnosis, time on HAART, current viral load, geriatric depression scale, and Mini-Mental State Examination score.

OR, odds ratio; SD, standard deviation; CI, confidence intervals; VL, viral load.

counts and detectable VL with disability. While we tend to think that low $\mathrm{CD}^{+}$cell counts, but particularly persistent viral replication, is associated with chronic immune activation and persistent inflammation causing corporal structural changes and bringing about changes that promote disability, we cannot rule out that disability itself caused by other factors hinders antiretroviral treatment adherence and promotes treatment and immunological failure. Another possible confounding factor is the association between delayed diagnosis and treatment initiation, which is common in our center and in other countries in the region, ${ }^{30}$ and could lead to poor $\mathrm{CD}^{+}$recovery and disability associated with sequels of opportunistic infections.

Although we did not formally assess the role of delayed diagnosis, through the use of multivariate regression models, we controlled for the possible confounding effect of disability associated with opportunistic infections or its sequels that occur more frequently among patients with low $\mathrm{CD} 4^{+}$cell counts. In addition, the sample size, particularly in the assessment of the association between $\mathrm{CD} 4^{+}$and HIV VL, led to the formation of small groups in each category. On the other hand, the validity of our results is supported by the use of previously validated tools for the assessment of disability in the context of recent (no more than a month old) determinations of $\mathrm{CD}^{+}$cell counts and viral loads. It is also worth emphasizing that other factors classically associated with disability did not show an independent association in this population or, if present, the strength of such an association was considerably lower in comparison with age, educational level, or HIV/AIDS markers.

In conclusion, in this cross-sectional study age, educational level, low current $\mathrm{CD}^{+}$cell counts, and detectable viral loads are independently and robustly associated with prevalent disability in individuals $>50$ years of age with HIV/ AIDS. Since both $\mathrm{CD} 4^{+}$cell counts and VL are indicators of the effectiveness of treatment in patients receiving HAART, the results of the present study might suggest that the risk of disability could be reduced in this population by optimal antiretroviral treatment. Disability is a predictor for adverse health-related outcomes including institutionalization, falls, and mortality; therefore, to be able to identify the correlates of this geriatric syndrome provides new insight into the significance of evaluating ADL and IADL disability in adults with HIV infection and AIDS regardless of their age, and should be further investigated to clarify its nature.

\section{Acknowledgments}

The corresponding author is particularly grateful to Drs. Parra-Guerra and Dávila-De la Llave for their unconditional support for this research.

\section{Author Disclosure Statement}

J.C.R.: speaker, Pfizer. B.C.R.: speaker, BMS and Stendhal. J.S.M.: grants, BMS, Pfizer, MSD, Gilead; speaker, MSD, Gilead, Stendhal, Viiv; consultant, MSD, Pfizer, Gilead, Viiv.

\section{References}

1. Centers for Disease Control and Prevention: HIV/AIDS among persons aged 50 and older: CDC HIV/AIDS facts. 2011, Washington, DC: US Department of Health and Human Services.

2. Vigilancia epidemiológica de casos de VIH/SIDA en México. Registro Nacional de Casos de Sida: Actualización al 30 de septiembre de 2014 (CENSIDA). Available at www.censida.salud.gob.mx/descargas/epidemiologia/RN_ 3er_trim_2014_.pdf. Accessed October 27, 2015.

3. Smith RL, de Boer R, Brul S, et al.: Premature and accelerated aging: HIV or HAART? Front Genet 2012;3: 328.

4. Pathai S, Lawn SD, Gilbert CE, et al.: Accelerated biological ageing in HIV-infected individuals in South Africa: A case-control study. AIDS 2013;2:2375-2384.

5. Morgan EE, Iudicello JE, Weber E, et al.: Synergistic effects of HIV infection and older age on daily functioning. J Acquir Immune Defic Syndr 2012;61:341-348.

6. Erlandson KM, Schrack JA, Jankowski CM, et al.: Functional impairment, disability, and frailty in adults aging with HIV-infection. Curr HIV/AIDS Rep 2014;11: 279-290. 
7. Barberger-Gateau $\mathrm{P}$, Rainville $\mathrm{C}$, Letenneur L, et al.: A hierarchical model of domains of disablement in the elderly: A longitudinal approach. Disabil Rehabil 2000;22:308-317.

8. Maione P, Perrone F, Gallo C, et al.: Pretreatment quality of life and functional status assessment significantly predict survival of elderly patients with advanced non-small-cell lung cancer receiving chemotherapy: A prognostic analysis of the multicenter Italian lung cancer in the elderly study. J Clin Oncol 2005;23:6865-6872.

9. Repetto L, Fratino L, Audisio RA, et al.: Comprehensive geriatric assessment adds information to Eastern Cooperative Oncology Group performance status in elderly cancer patients: An Italian Group for Geriatric Oncology Study. J Clin Oncol 2002;20:494-502.

10. Flood KL, Carroll MB, Le CV, et al.: Geriatric syndromes in elderly patients admitted to an oncology-acute care for elders unit. J Clin Oncol 2006;24:2298-2303.

11. Gobbens RJ, van Assen MA, and Schalk MJ: The prediction of disability by self-reported physical frailty components of the Tilburg Frailty Indicator (TFI). Arch Gerontol Geriatr 2014;59:280-287.

12. Lawton MP and Brody EM: Assessment of older people: Self-maintaining and instrumental activities of daily living. Gerontologist 1969;9:179-186.

13. Mahoney FI and Barthel DW: Functional evaluation: The Barthel index. Md State Med J 1965;14:61-65.

14. Yesavage JA: Geriatric Depression scale. Psychopharmacol Bull 1988;24:709-711.

15. Folstein MF, Folstein SE, and McHugh PR: "Mini-mental state". A practical method for grading the cognitive state of patients for the clinician. J Psychiatr Res 1975;12:189-198.

16. Avila-Funes JA, Pina-Escudero SD, Aguilar-Navarro S, et al.: Cognitive impairment and low physical activity are the components of frailty more strongly associated with disability. J Nutr Health Aging 2011;15:683-689.

17. Dorantes-Mendoza G, Avila-Funes JA, Mejia-Arango S, et al.: [Factors associated with functional dependence in older adults: A secondary analysis of the National Study on Health and Aging, Mexico, 2001]. Rev Panam Salud Publica 2007;22:1-11.

18. Greene M, Covinsky K, Astemborski J, et al.: The relationship of physical performance with HIV disease and mortality. AIDS 2014;28:2711-2719.

19. Yarasheski KE, Scherzer R, Kotler DP, et al.: Age-related skeletal muscle decline is similar in HIV-infected and uninfected individuals. J Gerontol A Biol Sci Med Sci 2011; 66:332-340.

20. McDermott AY, Terrin N, Wanke C, Set al.: CD4+ cell count, viral load, and highly active antiretroviral therapy use are independent predictors of body composition alter- ations in HIV-infected adults: A longitudinal study. Clin Infect Dis 2005;41:1662-1670.

21. Falutz J: Growth hormone and HIV infection: Contribution to disease manifestations and clinical implications. Best Pract Res Clin Endocrinol Metab 2011;25:517-529.

22. Kosmiski L, Kuritzkes D, Hamilton J, et al.: Fat distribution is altered in HIV-infected men without clinical evidence of the HIV lipodystrophy syndrome. HIV Med 2003; 4:235-240.

23. Yin MT, Zhang CA, McMahon DJ, et al.: Higher rates of bone loss in postmenopausal HIV-infected women: A longitudinal study. J Clin Endocrinol Metab 2012;97:554-562.

24. Ling PR, Schwartz JH, and Bistrian BR: Mechanisms of host wasting induced by administration of cytokines in rats. Am J Physiol 1997;272:E333-E339.

25. Belec L, Meillet D, Hernvann A, et al.: Differential elevation of circulating interleukin-1 beta, tumor necrosis factor alpha, and interleukin-6 in AIDS-associated cachectic states. Clin Diagn Lab Immunol 1994;1:117-120.

26. Scherzer R, Heymsfield SB, Lee D, et al.: Decreased limb muscle and increased central adiposity are associated with 5-year all-cause mortality in HIV infection. AIDS 2011;25: 1405-1414.

27. Tang AM, Jacobson DL, Spiegelman D, et al.: Increasing risk of $5 \%$ or greater unintentional weight loss in a cohort of HIV-infected patients, 1995 to 2003. J Acquir Immune Defic Syndr 2005;40:70-76.

28. Richert L, Dehail P, Mercie P, et al.: High frequency of poor locomotor performance in HIV-infected patients. AIDS 2011;25:797-805.

29. Erlandson KM, Allshouse AA, Jankowski CM, et al.: Functional impairment is associated with low bone and muscle mass among persons aging with HIV infection. J Acquir Immune Defic Syndr 2013;63:209-215.

30. Crabtree-Ramírez B, Caro-Vega Y, Shepherd BE, et al.: Cross-sectional analysis of late HAART initiation in Latin America and the Caribbean: Late testers and late presenters. PLoS One 2011;6:e20272.

Address correspondence to: José Alberto Ávila-Funes Departmento de Geriatría

Instituto Nacional de Ciencias Médicas y Nutrición Salvador Zubirán

Vasco de Quiroga 15

CP 14000 Tlalpan, Distrito Federal México

E-mail: avilafunes@live.com.mx 